\title{
ON DEVELOPING A SYSTEMATIC METHODOLOGY FOR ANALYZING CATEGORIES IN TALK-IN-INTERACTION: SEQUENTIAL CATEGORIZATION ANALYSIS
}

\author{
Cade Bushnell
}

\begin{abstract}
In this essay, I discuss one direction for developing a systematic, data-grounded analysis of categories in talk-in-interaction. This framework is developed around two main analytical foci. The first examines how the participants themselves work to publicly associate some set of normatively and morally accountable actions, rights, obligations, entitlements, attributes, etc. (i.e., category-bound predicates; see, e.g., Jayyusi 1984; Sacks 1972a, 1972b, 1979, 1992; Watson 1978) to the various turn- and sequence-generated categories built up by their actions-in-talk, and to explicit categorial formulations (i.e., labels, metonyms, descriptions, etc.) and their indexers. The second is concerned with how the participants recognizably and relevantly accomplish the sequential organization and turn by turn management of their categorization work. The notions of rhetorical (see Edwards 1991, 1997, 1998), conditional (Schegloff 1968, 1972), and retro-relevance (see Schegloff 2007a on 'retro-sequences'), along with response priority (Bilmes 1993, 1995; see also Bilmes 1988) are introduced as sequential analytical tools for developing a systematic, data-based analysis of these practices.
\end{abstract}

Keywords: Categories in talk; Sequence; Relevance; Conversation analysis; Membership categorization analysis.

\section{Introduction}

As Schegloff argues in regard to analyzing categories in talk-in-interaction, "[the issue is] not whether we can or should make a category out of [some element in the talk], but whether they - the parties to the conversation - do so, and, if they do, what that sounds or looks like" (2007b: 477; original emphasis). He further maintains that a failure to ground an analysis in the participants' actual conduct may result in the analyst "promiscuously introducing into the analysis what the writing needs for the argumentin-progress" (2007b: 476). In this paper, I consider one approach to a systematic, datagrounded sequential analysis of categorial actions and formulations in interaction. This approach involves a synthesis of sequential conversation analysis (e.g., Sacks 1992; Schegloff 2007a) and membership categorization analysis (e.g., Sacks 1972a, 1972b, 1979, 1992; Hester and Eglin 1997; Housley and Fitzgerald 2002, 2009). Below, I will refer to this methodological approach as sequential categorization analysis, in order to 
distinguish it from the individual approaches of conversation and membership categorization analysis, while at the same time acknowledging these approaches as being the major conceptual contributors. In particular, sequential categorization analysis draws upon membership categorization analysis in order to operationalize membership category, and to clarify how categories may be invoked in talk. From sequential conversation analysis are drawn the notions of rhetorical (see Edwards 1991, 1997, 1998), conditional (Schegloff 1968, 1972), and retro-relevance (see Schegloff 2007a), and response priority (Bilmes 1993, 1995, see also Bilmes 1988). These notions enable an analytic description of how the participants relevantly sequentially deploy and organize their category work in talk-in-interaction.

Below, I first provide a brief description of the data. Following this, I review some of the key viewpoints pertaining to the viability of categorial analysis in general, and suggest two major issues that must be addressed in order to develop a systematic analytic framework. Then, in Section 4, I discuss and operationalize membership category, and explain how the sequential analytic notions of rhetorical (see Edwards 1991, 1997, 1998), conditional (Schegloff 1968, 1972), and retro-relevance (see Schegloff 2007a), and response priority (Bilmes 1993, 1995, see also Bilmes 1988) may be applied to an analysis of categories in talk. Then, in Section 5, I employ these notions in an analysis of the ways in which participants in a spate of talk-in-interaction organize their categorization work.

\section{Data}

The data examined in the present paper are drawn from the following two sources:

(1) A corpus of audio and video recordings capturing a week in the life of an American man in his fifties, Dan, who is a professor at a Japanese university. The majority of the audio recordings were made by Dan himself; after having obtained consent from his co-workers, students, and so forth, Dan carried a small digital recording device with him throughout the day, which he essentially turned on at the start of the day and then turned off at the end of the day. These audio recordings include a number of Dan's professional interactions, such as consultations with students and conversations with colleagues, and his interactions at a barbeque party held by his department, as well as some interactions from his private life, such as a dinner conversation with an old friend in town for a visit. The data from this corpus appearing in the current paper come from this dinner conversation (i.e., Excerpts 1 and 6).

(2) A fragment from an interaction observed by the researcher during a seminar on Japanese sociolinguistics at an American university. Because this data was encountered spontaneously, I was not able to make an audio or video recording. However, because I intuitively found the interaction to be intriguing (for reasons I could not put my finger on at the time), I ended up making detailed fieldnotes. It may be noted that, although mechanically or digitally recorded data is considered to be the sine qua non of conversation analysis, analysts do occasionally, for various reasons, also provide remembered or noted down instances to illustrate their arguments (see, e.g., Jefferson 2007; Schegloff 1992b, 2007a). Excerpts 2a and 2b come from one such instance which was noted down in the absence of a recording device. 
All data are transcribed in accordance with conversation analytic conventions, as outlined in Jefferson (2004). Additionally, in order to accommodate the presentation of foreign language (i.e., Japanese) materials, I adopt the format used in the volume edited by Nguyen and Kasper (2009); the data are shown in a three-tiered format, with a Romanized $^{1}$ version of the Japanese utterance appearing in the first tier, and a word-forword gloss and English equivalent shown in the second and third tiers, respectively.

\section{Sequence and category}

Sequential conversation analysis has developed a highly systematic methodology for the analysis of talk-in-interaction based on its publicly co-accomplished nature (see, e.g., Sacks, Schegloff, and Jefferson 1974; Schegloff 1968, 1972). In particular, one of the main analytic goals of conversation analysis is to describe the methods by which the participants in talk accomplish their talk as orderly and mutually recognizable, and to describe these not from the perspective of the analyst, but from the perspectives of the participants themselves. Conversation analytic research has found that almost every turn at talk is understood as being produced as a recognizable next action in light of a (most often the) prior turn. Likewise, a current turn at talk (re)creates the sequential context in which the subsequent turn must be produced. Hence, each subsequent turn at talk necessarily works to publicly document the analysis by its producer of the prior turn. This fact allows the researcher to gain an understanding of the organization of social action from the perspective of the participants themselves in terms of the sequential relevance of the action(s).

Categorization analysis, on the other hand, has been criticized as tending to rely on relatively idiosyncratic and ad hoc procedures (Bilmes, personal communication; Schegloff 2007b; Stokoe 2012). Schegloff (2007b) suggests that research examining categories in talk has thus far failed to base its analyses in the unfolding sequential structure of the talk, arguing that analyses have been grounded not "in the conduct of the parties, [but] in the beliefs of the writer" (2007b: 476). Schegloff's criticism seems to be aimed specifically at membership categorization analysis (MCA), which seeks to understand and describe members' reflexive methods of organization and interpretation. This project has often relied upon (or even treated as data) the researcher's own understandings of categorial implications, inferences and formulations (see, e.g., Francis \& Hart 1997; Onuki \& Matsuki 2003; Sacks 1972a, 1972b, 1992).

However, Carlin (2010) strongly criticizes the picture of MCA put forth by Schegloff (2007b). In so doing, he points out that Schegloff formulates an "ideological version" of MCA based on "Sacks-according-to-Schegloff" (2010: 257). Furthermore, Carlin notes that Schegloff (2007b) seems to artificially segregate the categorial aspects of talk away from its sequential aspects, and to suggest that analysts are faced with an either/or choice, that is, they may attend to either category or sequence, but not both. As Watson $(1994,1997)$ argues, such a stance is problematic because a disattention to the categorial aspects of talk does not result in such aspects becoming inert or inoperative in the participants' interactional practices. Rather, as Watson suggests, regardless of whether it is placed under analytic scrutiny or not, participants ongoingly and indisputably engage in categorization as a part of their "documentary method" (see

\footnotetext{
${ }^{1}$ A modified version of the Kunrei-shiki system is used.
} 
Garfinkel 1967). Thus, according to Watson, because of the reflexively intertwined nature $^{2}$ of sequence and category, a purely sequential analysis must necessarily and unrelievedly rely on a tacit analysis of the participants' categorization practices. In this way, as Watson (1997) maintains, both sequence and category are inextricable aspects of participants' interactional practices. Thus, a strong impetus is provided for developing a methodology capable of producing systematic analyses of both of these aspects, and their reflexively intertwined nature.

Stokoe (2012) echoes the arguments made by Watson and others, and takes these as a warrant to "move forward" with membership categorization analysis. She rejects the notion that membership categorization analysis is necessarily an unsystematic and undisciplined approach by suggesting five principles to guide data collection, analysis and corpus construction. She then goes on to provide a comprehensive review of what she terms to be the ten "key concepts" (2012: 280-281) of membership categorization analysis, gathered from her reading of notions developed by Sacks and subsequent researchers (e.g., Watson 1978; Jayyusi 1984). In her analyses of a number of excerpts taken from both a scripted interaction (i.e., a scene from a American situational-comedy television program) and naturally occurring interactions, she describes the participants' accomplishment of their local social order in and through their production of, and alignment with or resistance to various gender-related membership categories. She argues strongly that her analyses demonstrate the systematic applicability of the five guiding principles and ten "key concepts" she outlines prior to her analyses in order to describe the participants' categorial work as a "robust feature of particular action-oriented environments" (2012: 299).

While research done by Watson $(1978,1997)$, and later Stokoe $(2009,2012)$, for example, clearly demonstrates the systematic application of a set of procedures for analyzing categories in talk, there is still a need for further methodological refinements. In particular, although both Watson $(1978,1997)$ and Stokoe $(2009,2012)$ invoke the notion of relevance in their analyses and discussions of their participants' deployment of membership categories in the talk, the notion seems to remain somewhat obscure and intuitive. In the following sections, I develop a more nuanced view of the notion of sequential relevance, and demonstrate that such a view provides a further resource, or "key concept," to use Stokoe's (2012) term, by which analyses of the participants' realtime use of categories may be firmly grounded in the conduct of the participants themselves as they jointly unfold for each other the emerging sequential structure of the talk.

I believe that there are two major issues that must be dealt with in order to develop a systematic analytic framework capable of dealing with both sequence and category. The first of these is defining the phenomenon to be dealt with, that is, membership category, and being able recognize "what [it] sounds or looks like" (Schegloff 2007b: 477) in the talk. The second issue is understanding how to gain an analytical purchase on such categories and their sequential relevance while maintaining a data grounded, participant relevant approach. I consider the first issue of defining the

\footnotetext{
${ }^{2}$ Using as an example a medical consultation, Watson (1997) argues, for instance, that for the participants of such an interaction, the categories "doctor" and "patient" simultaneously inform and are informed by the sequential structure of the interaction in a reflexive manner. Furthermore, Watson holds, these two aspects (i.e. sequential and categorial) jointly and reflexively work to make the interactional pattern visible and describable as being a "medical consultation" - a pattern which itself reflexively "folds back on the talk" to inform and make intelligible both its sequential and categorial aspects.
} 
phenomenon in the next section, after which I provide an analytic demonstration addressing the second issue of developing a participant relevant description of category work.

\section{Sequential categorization analysis}

\subsection{Operationalizing "membership category"}

From a purely CA perspective, identity is accomplished in and as local action: Cocreated, worked up, maintained, and adjusted, aligned with or contested in, through, and for specific interactional occasions. Thus, identity is understood as being inextricably and reflexively related to the locally managed interactional order. A CA analysis of identity involves describing the participants' orientations to one another through documenting their publicly displayed actions-in-talk. In other words, identity is seen as something that participants co-constitute through an application of fundamental interactional resources such as turn-taking, adjacency pairs, repair, and so forth.

Zimmerman (1998), for example, puts forth the notions of discourse, situated and transportable identity. According to Zimmerman (1998: 88), discourse identities are linked to the "proximal context" of an interaction, that is, they are constituted in, through, and for specific turns and sequences at talk. Thus, they are analytically available in the displayed actions and understandings of the participants in talk. Zimmerman's situated identities, on the other hand, are linked to the "distal context" of an interaction and "articulated" with discourse identities such that they are made visible, worked up, and managed through various discourse identities across multiple turns and sequences (1998: 88). It is important to note, however, that Zimmerman does not refer to the various types of identity in his framework in terms of membership categories, potentially attended by sets of category-bound predicates (discussed in more detail below; see, e.g., Watson 1978; Jayyusi 1984). Thus, the focus of Zimmerman's identities seems to be mainly on the realization of local action within a spate of talk. For example, according to Zimmerman's framework, participants may co-construct and orient to various identities such as questioner, answerer, call-taker, caller, and so forth as they jointly bring off sequences of local action. This link between identity and local action is also present in Sacks' notion of membership category. However, as Lepper (2000: 16) notes, Sacks was also concerned with developing formal descriptions of the pragmatic and cultural understandings which underpin such local courses of action.

In regard to membership categories, Schegloff $(2007 b, 2007 c)$ notes that there seems to be a number of different objects in talk which may be (mis-)labeled as categories, i.e., attributions, reference to persons, descriptions, and so forth. Schegloff (2007b: 477) asks in particular, "[i]s any attribute or description to be treated as a category in a categorization device of the sort Sacks meant to be describing?" Sacks (1972a, 1972b, 1979, 1992) conceptualized membership categories as being groupings of two or more social members, which are associated with, or bound to, certain actions. Sacks further notes that categories may constitute "a locus for a set of rights and obligations concerning [an activity]" (1972a: 37), and that categories may be assembled into collections of related groupings, or membership categorization devices (MCD) (e.g., 1972a, 1972b, 1979, 1992). Subsequent research by Watson (1978) and Jayyusi (1984) expanded upon and further refined Sacks' notions concerning the relation 
between category and actions, rights and obligations into the broader notion of category-bound predicate, which may entail actions, attributes, rights, responsibilities, knowledge, authority, and so forth. Based on these ideas, we may operationalize membership category as being a grouping of two or more social members associatable with some set of attributes, actions, knowledge, and so forth.

In my view, there seem to be (at least) three distinct ways in which participants invoke categories in their talk, each of which variously impose differing analytical exigencies. The first way is directly tied to basic turn-by-turn actions in talk, such as questioning and answering (see, e.g., Housley and Fitzgerald 2002; Psathas 1999; Watson 1994). The second way is closely articulated with basic actions-in-talk such that certain types of question and answer sequences might be related to categories such as caller and call-taker (Psathas 1999). I will refer to these as turn-generated (following Watson 1994) and sequence-generated categories, respectively. These ways of invoking categories are intimately related with the interactional work of "doing being $X$ for one another." Furthermore, although these category types may not be explicitly labeled by the participants themselves in their talk, they are made visible and treated as categories, associated with certain attributes, actions, rights, accountabilities, and so forth, through the participants analytically describable moves in talk-in-interaction. The following excerpt provides an illustration. Prior to the excerpt, the participants, Dan and Saburoo, were discussing udon "thick noodles." When Dan first came to Japan, he lived in the Osaka area, and then moved to eastern Japan. Saburoo, on the other hand, was living in eastern Japan, but prior to Excerpt 1, had moved to the Osaka area. The mukoo "over there" in line 1 seems to refer to the Osaka area.

(1) Turn and sequence-generated categories

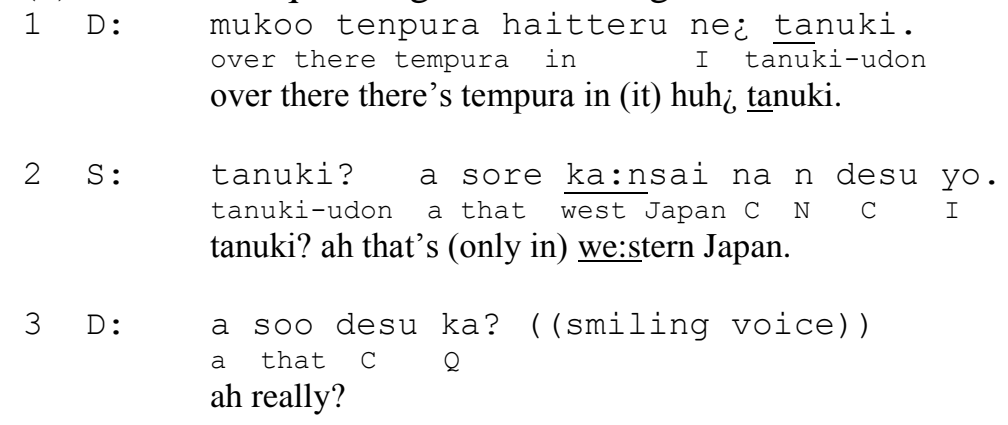

Prior to Excerpt 1, Dan and Saburoo were discussing tanuki udon (thick noodles and broth with either fried bits of batter [eastern Japan-style] or tempura [western Japanstyle] in it). Saburoo states that, in eastern Japan, tanuki udon has something resembling the dregs from tempura in it. In line 1, Dan deploys mukoo tenpura haitteru ne $\dot{i}$ tanuki ("tempura comes in [it] over there [i.e. in western Japan] huh $i$ tanuki"). Through making an observation of a situation (i.e., that tanuki udon comes with tempura in it in western Japan) known in common to both Dan and Saburoo (note that this epistemic stance is explicitly marked by the use of $n e$ ), and through the deployment of prosody, this utterance presents the differences between the two versions of tanuki-udon being discussed by the participants as a "puzzle" (Antaki \& Widdicombe 1998). As such, it works to make relevant an explanation or clarification from Saburoo. Notably, this action potentially makes relevant (a) the turn-generated categories of questioner/answerer and (b) the sequence-generated categories of expert/novice, along with associated actions, epistemic entitlements, and so forth. 
In line 2, Saburoo provides an answer to the puzzle proposed by Dan's line 1 by stating that only tanuki udon in western Japan comes with tempura in it. This action serves to endorse the categorization framework proposed by Dan's line 1. In line 3, Dan responds with a soo desu $k a$, which is produced with a prosodic contour that makes it hearable as displaying an affective stance (Ochs 1993, 1996) of mild surprise. This action claims a change of state (Heritage 1984) by ostensibly receipting Saburoo's line 2 as news, and thus simultaneously displaying an understanding of the activity being assembled in the unfolding talk as being an informing - thus renewing the categorization framework proposed and endorsed in the preceding talk. An important point is that the participants themselves do not overtly label the categories they make relevant, that is, they do not explicitly refer to one another as questioner, expert, and so forth. However, through the participants' use of turn and sequence to build up, manage, and display their understandings of this categorization framework, it becomes a publicly documented and analytically demonstrable matter.

The third way of invoking a category involves an overt formulation or indexing of the category through the use of explicit vernacular labels, metonyms, metaphors, and other forms of description. The work of associating such categorial formulations with category-bound predicates may constitute one project of the participants' talk; a second and related project is the use of overtly formulated categories as devices through which social actions, such as blaming, appealing, and so forth, may be assembled (see, e.g., Edwards 1997; Sacks 1972a; Watson 1978). I will refer to this type of category as formulation generated category.

Excerpt 2 is from a seminar on Japanese sociolinguistics at a university in the United States. Prior to the sequence, the teacher (T), a Japanese woman, was lecturing on the growing trend among contemporary Japanese not to use kenjoogo "humble honorifics."

(2a) Formulated categories

1 ( $T$ (gazing in turn at $B, C$, and D)) do we even use that
kind of language anymore?

In line 1, T deploys the first person plural pronoun we, which here performs a complex set of actions. One of these actions is to assemble a subset of the co-present participants together into the same category - notably, $\mathrm{T}$ simultaneously directs her gaze to a group of seminar students, i.e., B, C, and D, in turn; another is to create a distinction between that category and other possible categories to which the label they might be attributed (He 2004; Sacks 1992). A further action performed here by we is to make relevant a much larger category (Sacks 1992 v1: 335). This larger category is apparently inclusive of an indefinite set of contemporary (cf. T's use of the adverbial phrase even...anymore) members co-categorizable with T, B, C, and D. Notably, all of these participants are first language speakers of Japanese, and "categorizable on-sight" (Paoletti 1998) as Japanese. These aspects of T's lines 1 and 2 utterance work together to make her line 1 "we" hearable as indexing we Japanese, a possible metonym for the membership category Native speaker, ${ }^{3}$ and to make T's question hearable specifically as being

${ }^{3}$ The Japanese term that most closely translates to "native speaker" (i.e., bogowasya) seems to be a more technical term than its English counterpart, and is not typically used in casual talk. When I asked an informant about why this might be the case, she said that because nihonjin "Japanese" are the only possible native speakers of the Japanese language, everyone else is a nonnative speaker by default. 
relevantly answerable only by $\mathrm{B}, \mathrm{C}$, or $\mathrm{D}$, who are co-categorizable with $\mathrm{T}$ on the basis of (at least) appearance and language expertise, and overtly co-categorized with $\mathrm{T}$ (and an indefinite set of contemporary Japanese) by the pronoun we and the use of gaze.

At its most basic level, the practice of membership categorization involves the activity of treating a certain set of attributes, actions, activities, and other predicates as being associated with a specific group of (at least two) members. In Excerpt 2a, it would appear that $\mathrm{T}$ is treating certain epistemic and participatory rights and entitlements as being bound to the category into which she has assembled herself and the seminar students B, C, and D via her talk and gaze (see Jayyusi 1984 on "perceptually available categories"). It is therefore tempting to analyze T's lines 1 and 2 actions as making relevant certain membership categories such as Native speaker or Japanese. However, it is of crucial importance to note that doing so would result in the analyst him or herself engaging in the members' practice of categorization, i.e., although they have produced certain actions which may appear to an analyst to implicate the relevance of certain membership categories, the participants themselves have not yet displayed an understanding of their actions as making such categories relevant. For an analyst to induce categorial implications from the actions of the participants in such a case seems to be exactly the kind of analytic procedure to which Schegloff's (2007b) criticism is aimed. In order to determine whether an analysis of T's actions as working to make relevant the category of Native speaker is warrantable, we must observe the understandings subsequently displayed by the participants themselves in the unfolding sequential talk.

(2b) Formulated categories

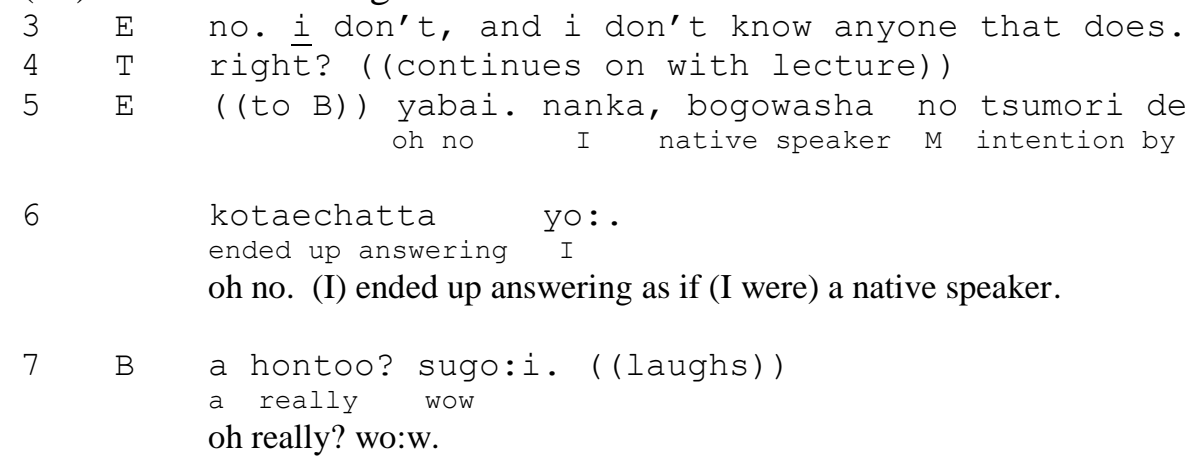

Interestingly, the interaction continues in line 3 with $\mathrm{E}$, a second language speaker of Japanese, providing the second-pair part to T's question. In line 4, T notably appears to treat E's second pair-part to her question as unproblematic. ${ }^{4}$ Thus, at this point, it would seem that T's lines 1 and 2 actions may not have made Native speaker relevant after all. However, note that in line 5, E treats his line 3 actions as being accountable. In so doing, E (a) displays an orientation to T's lines 1 and 2 as having been relevantly answerable by an incumbent of the category bogowasha ("native speaker") - notably formulated here by E as an explicit categorial label, and (b) removes himself from this category, which (c) works to associate bogowasha with (unspecified) category-bound

Thus, in casual Japanese conversation, it would seem that nihonjin "Japanese" entails bogowasya "native speaker."

${ }^{4}$ I write "appears" due to the fact that the absence of mechanically recorded data prevents a precise analysis. It is worth mentioning, however, that I recorded in my field notes no noticeable indication of a problem prior to or in association with $\mathrm{T}$ 's response to $\mathrm{E}$. 
predicates not attributable to himself. In line 7, B, a first language speaker of Japanese sitting next to E, receipts E's account as newsworthy and hearably displays an affective stance (Ochs 1993, 1996) of amusement, actions which further work to constitute bogowasha as a category which is bound to certain (unspecified) predicates not attributable to E. Thus, T's lines 1 and 2 actions are treated by the participants themselves as having made Native speaker relevant to the interaction. Importantly, they accomplish this through publicly deploying overt categorial formulations (in this especially perspicuous case, both a metonym, "we," and an overt categorial label, bogowasha) which work to display their understandings of the developing course of actions-in-talk to one another, and to the analyst.

There are obvious similarities between what I have just described as turn-, sequence-, and formulation-generated categories, and Zimmerman's (1998) notions, mentioned above, of discourse, situated, and transportable identities - indeed, they are both based upon a common ethnomethodological groundwork; below, I briefly discuss some of the important differences between these two frameworks. First, there are fundamental differences in what might be referred to as the partitioning values of the two frameworks. Namely, (1) turn-generated and sequence-generated categories both correspond to, and more delicately analyze, what Zimmerman (1998) refers to as discourse identity; (2) Zimmerman's situated identities do not directly correspond to any single category type within the framework I have proposed; (3) Zimmerman's framework makes no clear accommodations for the level of formulation-generated category, per se; and (4) Zimmerman's transportable identity has no clear categorial analog, but rather potentially constitutes one type of category-bound predicate (Omori 2008; see also Paoletti 1998). These differences are shown in Figure 1.

Figure 1: Comparison of my category types and discourse, situated, and transportable identity

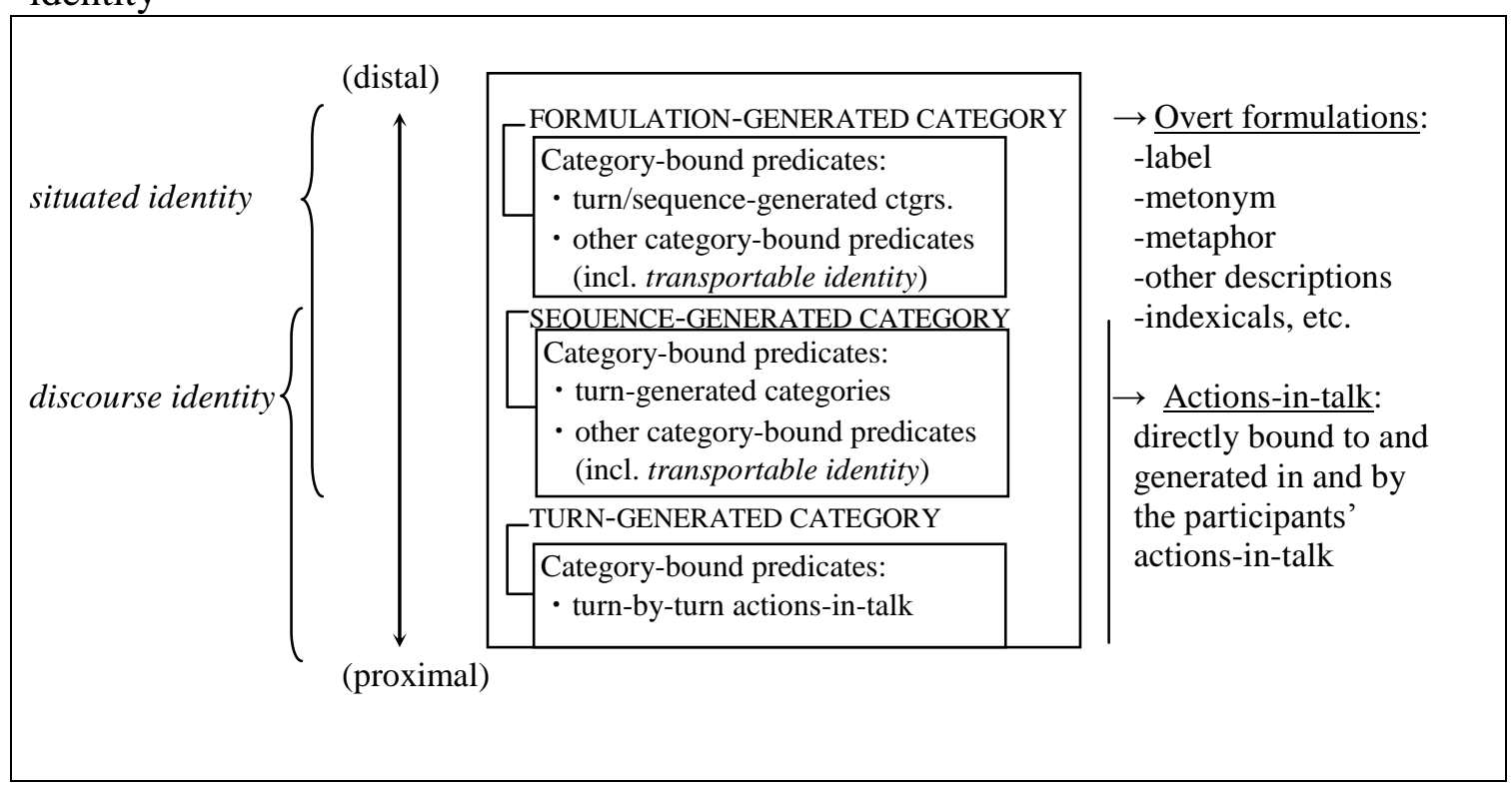

A second difference is that, as mentioned at the beginning of this section, Zimmerman's (1998) notion of discourse, situated and transportable identities is not conceptualized in terms of membership category, as operationalized above. This has important analytical consequences. Zimmerman (1998) argues that situated identities 
are interarticulated with discursive identities constituted through participants' turn by turn actions-in-talk. He also argues that participants work to align their situated identities with each other, and that misalignment is often treated as being problematic. For example, in his first data excerpt, Zimmerman analyzes an emergency call to a police station where the caller tries to engage the call-taking police officer in a round of riddle telling, resulting in a reproving and ending of the call by the police officer. In his analysis, he claims that a misalignment occurs in the identities of the participants. In particular, he notes that the call-taker treats as problematic the caller's failure to display an orientation to the call-taker as a police officer, and to the call itself as being relevantly made to the police (1998: 88-89). However, he does not provide a description of how (i.e., on what grounds) this misalignment is accomplished by the participants in terms of category work, and thus seems to be drawing on a tacit knowledge of categorial resources. A view informed by the framework I have proposed above would see the participants as negotiating the interactional relevance of certain categories based on their enactment of category-bound predicates. The misalignment noted by Zimmerman could thus be described in terms of a failure by the caller to produce the necessary category-bound actions for the sequence-generated category of emergency caller, instead producing actions potentially treatable as being bound to prankster. As such, the call-taker's actions of reproving the caller come into focus as simultaneously assembling the call-taker into the category of police officer, and displaying a orientation to the absence of morally accountable category-bound actions for emergency caller on the part of the person making the call.

\subsection{The sequential organization of categorization work}

Conversation analysis provides a robust set of analytic tools and notions whereby a participant relevant understanding of the sequential organization of talk may be developed. These include the organizations of turn-taking (e.g., Jefferson 1986, 1989; Sacks 1992; Sacks, Schegloff, \& Jefferson 1974; Schegloff 1987, 1996, 2000, 2006; see also Tanaka 1999a, 1999b, 2000 on Japanese turn-taking); paired actions, or sequences (e.g., Hayashi 2004; Jefferson 1972; Sacks 1975, 1992; Schegloff 1980, 1990, 2006, 2007; Schegloff \& Sacks 1973; see also Mori 2004; Nguyen 2008 on second language interactions); and repair (e.g., Gafaranga 2000; Goodwin 1980, 2007; Jefferson 1974, 1983; Sacks 1992; Schegloff 1979, 1991, 1992, 1997, 2000b; see also Carroll 2004; Hosoda 2000, 2006; Kasper 2006; Seedhouse 2004; Wong 2000 on second language interactions); among others (see, e.g., Hutchby \& Wooffitt 2008; Schegloff 2006; Have 2007 for overviews).

The ways in which the participants work up categorizations in real time interaction is necessarily sequentially accomplished. Thus, the principles and tools of sequential conversation analysis should also be applicable to the analysis of the participants' practices of categorization in talk. Of particular importance to sequential analysis is describing how the participants accomplish aspects of their talk as organized and mutually recognizable, and relevant. In the case of categorization work, I suggest that the following three notions of sequential relevance may be implicated in the participants' deployment and organization of categories in their talk-in-interaction. The first of these is what might be called rhetorical relevance (see Edwards 1991, 1997, 1998). Edwards notes that participants in interaction may work up and deploy categorial 
resources "in ways that attend, in sensitive detail, to what the other partner may and does say" (1997: 162; emphasis mine). In other words, participants may display in their categorization work an orientation to not-yet-realized-but-possible lines of action in the talk. Thus, rhetorical relevance works to make a categorization recognizable as being relevant based on foreseeable possible developments in the interaction. Though he himself does not use the term rhetorical relevance, this notion may be illustrated in Watson's (1978) analysis of two data excerpts from a suicide prevention hotline in the United Kingdom. Watson notes that the caller assembles certain MCDs, one of which is racial groups, and attributes certain category-bound predicates to these MCDs and the categories assembled into them to account for her current disfavorable circumstances, and to apportion blame. Interestingly, one of the actions simultaneously undertaken by the caller is to work up a self-categorization as a non-racist. Watson (1978: 109) argues that this action may have been produced with an eye to possible "[vulnerabilities which] may be invoked by others in order to undercut and discredit the account." Thus, in this case, the caller's categorization work is made recognizable as a sequentially relevant action in light of some foreseeable work by the call-taker to discredit or undercut her action of blaming.

The next notion of relevance is conditional relevance (Schegloff 1968, 1972). In regard to conditional relevance, Schegloff $(1968,1972)$ states that it obtains when a current action-at-talk calls for the occurrence of a second, such that if the second does not occur its absence is a noticeable and accountable event. Furthermore, when the second action is produced, it is seen by the participants as responding to the first action. This is the operating principle of adjacency pairs, as in the following example where Mar's "fine" is hearable as being called for by, and in response to, Ton's "how are you."

(3) Greeting/greeting adjacency pair (reproduced from Schegloff, 2007a: 22)

1 Ton: how are you.

2 Mar: fi::ne.

Thus, in adjacency pairs, one participant's actions call for and specifically constrain the next actions of the other participant, such that, for (invented) example, an invitation makes relevant an acceptance or declination, but not a greeting (see, e.g., Schegloff \& Sacks 1973; Schegloff 2007a).

(4) Invitation/greeting (invented)

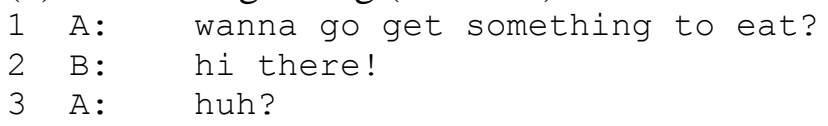

Furthermore, when a relevant second action is not provided, the producer of the initiating action may have grounds to pursue one (see, e.g., Bushnell 2011, in press; Schegloff 2007a), as in the following (invented) example, where, in line 3, A problematizes B's seemingly nonsense response to A's greeting.

(5) Pursuit of relevant response (invented)

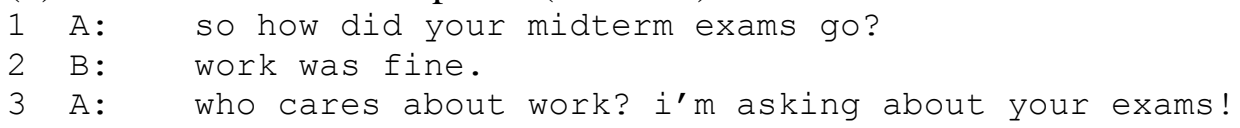


The type of relevance relationship indicated by the notion of conditional relevance is a prospective one (Schegloff 2007a: 217). In other words, this type of relevance relationship obtains when a current action calls for, and thus creates an expectation for a specific next action. Though he uses the term special relevance rather than conditional relevance, Day (1998), for example, emphasizes the sequentially responsive nature of his participants' categorization work, and argues that a participant's first position category-relevant action functions to make relevant and interactionally expected a specific responding action in second position (see also Watson $1978^{5}$ ). Furthermore, Watson (1997: 59-61) suggests that conditional relevance in both the sequential and categorial aspects of the talk may be mutually informative and intertwined such that it works to doubly specify the haecceity, or "just thisness" of the interactional sequence.

The third notion of relevance is retro-relevance. This principle of relevance seems to provide for a particularly cogent analysis of sequential categorization work. I believe that an important conceptual tool for understanding the operation of retrorelevance in categorization work is response priority (Bilmes 1993, 1995, see also Bilmes 1988). Briefly, Bilmes (1993: 391-392) defines the principle of response priority as being based upon (culturally available) "implicature-bearing series or scales," such that "if X is the first priority response, then any response other than X (including no response) implicates (when it does not assert) that $\mathrm{X}$ is not available or is not in effect, unless there is reason to suppose that it has been withheld." Though Bilmes $(1993,1995)$ does not argue so himself, response priority can operate in tandem with retro-relevance. ${ }^{6}$ In this case, in the interactional project of the ongoing accomplishment of intersubjectivity, the relevant and first priority business of every turn at talk is to initiate repair on, or otherwise work to revise the project of, the prior turn (or sequence, etc.; see Schegloff 1992). If this first priority business is passed on, the producer of the prior turn-at-talk has grounds to assume that his or her contribution has been understood, endorsed, and so forth (see, e.g., Sacks 1992; Schegloff 1992). Conversely, if the first priority business is initiated in a next turn, it retrospectively specifies a prior turn as warranting its relevance. For example, in an earlier paper in which he laid the theoretical groundwork for the formalization of response priority, Bilmes (1988) specifically discusses the issue of accusations and attributions, and the implicature surrounding their treatment in interaction by the participants. He notes that the priority response in this case is a contradiction $(\mathrm{X})$, which may be understood for the present purposes as one type of repair (or more precisely, correction)-relevant action. According to Bilmes (1988), a failure to contradict an accusation or attribution provides

${ }^{5}$ However, it seems to me that, though the conceptualization Watson (1978) outlines is compatible with Schegloff's $(1968,1972)$ notion of conditional relevance, the actual interactional phenomena that Watson (1978) analyzes as being conditionally relevant are actually retro-relevant. This suggests that the conceptualization of relevance Watson is working with is somewhat intuitive or vague. I discuss the notion of retro-relevance presently.

${ }^{6}$ Rather, Bilmes (1993, 1995) speaks of the principle of response priority in relation to conditional relevance. In this case, a set of responses made conditionally relevant by a prior turn is internally organized by response priority: If $\mathrm{X}$ represents a response aligning with the project of the prior turn, Y represents a response that does not align with this project, and a non-response (i.e., N) implicates $\mathrm{Y}$. An example of this would be a case where an invitation is issued. The invitation makes relevant a set of responses in which $\mathrm{X}$ is a response displaying acceptance, and $\mathrm{Y}$ is declination. A non-response, $\mathrm{N}$, implies declination. 
grounds for an inference that a contradictory response is not available, that is, that the accusation or attribution is true. ${ }^{7}$

The principle of response priority in retro-relevance provides a useful analytic tool by which to understand the ways in which participants in talk may treat the categorization work of a prior turn as retrospectively making relevant a priority response involving contradictory categorization work. This is shown schematically in Figure 2.

Figure 2: Relevance and response priority in sequential categorization work

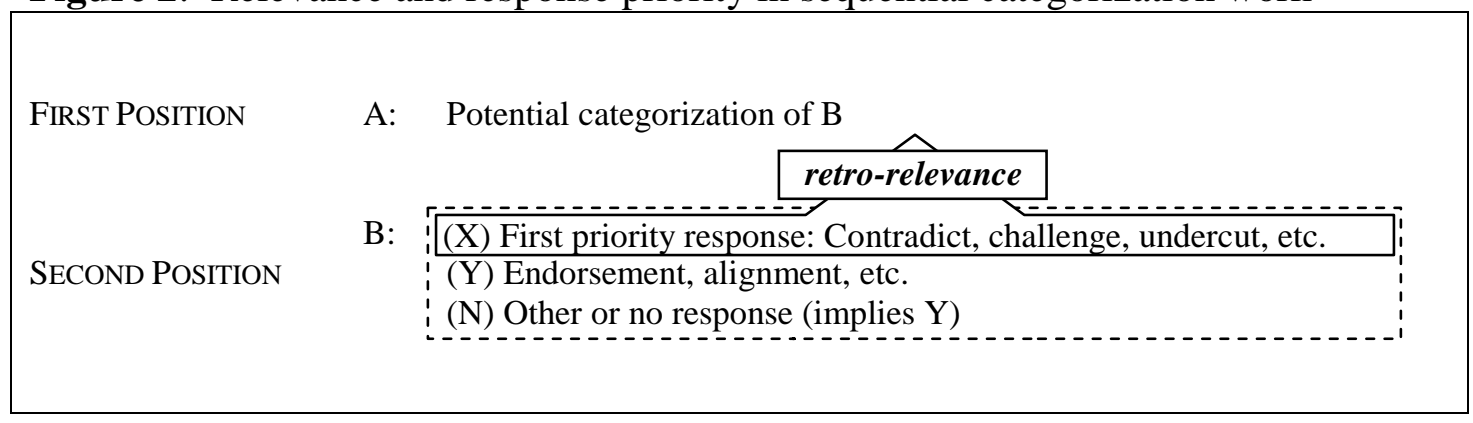

In Figure 2, A works up a potential categorization of B in first position. In such an environment, B is understood as endorsing that categorization unless he or she immediately contradicts, revises, undercuts, and so forth, in second position. In other words, in order to avoid being heard as endorsing (either explicitly or implicitly) A's categorization, B must provide a first priority response, which will be heard as relevant to the talk-just-now via retro-indicating A's first position categorization. Thus, categorization work organized around retro-relevance is conceptually analogous to repair, or what Schegloff (2007a: 217) calls "retro-sequences."

\section{An analytic demonstration: Putting the tools to work}

Excerpt 6 is taken from the same dinner conversation between Dan and Saburoo as was Excerpt 1, above. In my analysis of Excerpt 6, I draw on the sequential and categorization analytic tools discussed above in order to show how the participants sequentially co-construct a specific categorization framework, and that they make this categorization work visible and analyzable as such both through their deployment of overt categorial formulations and through their publicly displayed actions-in-talk. In particular, I draw upon the notions of retro-relevance and response priority to consider how Dan responds to a potential categorization of him by Saburoo.

(6) Naporitan

1. S: mukashi (.5) nihon no supagetti tte kechappu de
long ago

${ }^{7}$ Thus, it seems that the direction of the relevance relationship (i.e., conditional versus retro-) reverses the implicative polarity of response priority. In other words, in the case of prospective relevance, the priority response, $\mathrm{X}$, should deliver some form of the item made relevant by the prior turn while $\mathrm{Y}$ and $\mathrm{N}$ claim a problem with the deliverability of that item. In the case of retrospective relevance, on the other hand, it is the priority response $(\mathrm{X})$ to claim a problem, while anything other than $\mathrm{X}$ functions to claim or imply endorsement. 
2. $\quad$ ajitsuke shiteta $n$ odesu $\left[(y \circ) \cdot{ }^{\circ}\right.$

A long time ago, (they) used ketchup to season spaghetti in Japan.

3. D:

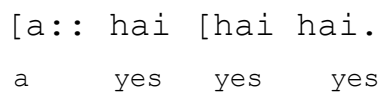

A:: yeah yeah yeah
4. S :

5. D: ${ }^{\circ}$ hai hai .

yes yes
${ }^{\circ}$ yeah yeah

6. $(.6)$ 7. S: naporita:n [toka (itte),

(it's) called like Neapolita:n

\author{
[a shittemasu? \\ know \\ oh (you) know?
}

8. D:

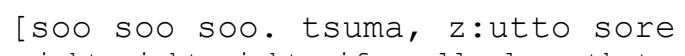

9.

tsu [kutteta.

was making

Right right right. (My) wife used to make that a:ll the time.
10. $\mathrm{S}:$

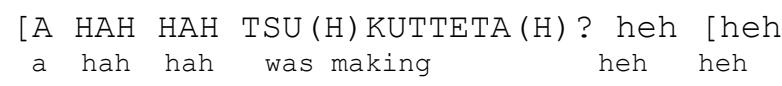

11. D:

$$
\begin{aligned}
& \text { [so }(h) \circ . \\
& \text { right } \\
& \text { ye(h)ah. }
\end{aligned}
$$

Prior to this excerpt, the participants were discussing the food that Dan had prepared for them and how he had used some unorthodox seasonings. In lines 1 and 2, Saburoo makes a statement regarding the use of ketchup to season spaghetti. In particular, he formulates this practice as being a specifically Japanese one (nihon no "of Japan") that took place in the past (mukashi "long ago"). Furthermore, Saburoo's utterance displays a stance of epistemic authority regarding this practice through deployment of the utterance final token yo (Kamio 1997). Thus, Saburoo's turn is hearable as potentially working to self-categorize Saburoo as a Japanese old-timer, with epistemic authority concerning the past Japanese practices in question, while simultaneously categorizing Dan as a foreign newcomer, ${ }^{8}$ who is unknowledgeable of these practices (see, e.g., Heritage \& Raymond 2005; Heritage 2012; Raymond \&

${ }^{8}$ It is interesting to note that Dan is visibly Caucasian, and that he hearably speaks Japanese with an American English accent - features potentially available as category-bound predicates of the category foreigner. 
Heritage 2006). The analytic task is now to show if the participants themselves understand lines 1 and 2 in this way, and if so, how they publicly document their understandings for each other, and how they manage the contingencies created by Saburoo's-utterance-so-understood.

Notably, in line 3, Dan overlaps Saburoo's "desu yo" with an immediate first priority response (Bilmes 1993, 1995), ${ }^{9}$ that is, a contradiction to the categorization framework hearably made relevant by Saburoo's lines 1 and 2 based on Dan's own claim of knowledge concerning these practices. This contradictory response is relevantly accomplished by Dan at this moment in retrospective reference to the Saburoo proposed categorization framework. In other words, a relationship of retrorelevance obtains.

Figure 3: Dan's response to Saburoo's potential categorization (Excerpt 6, lines 1 to 3)

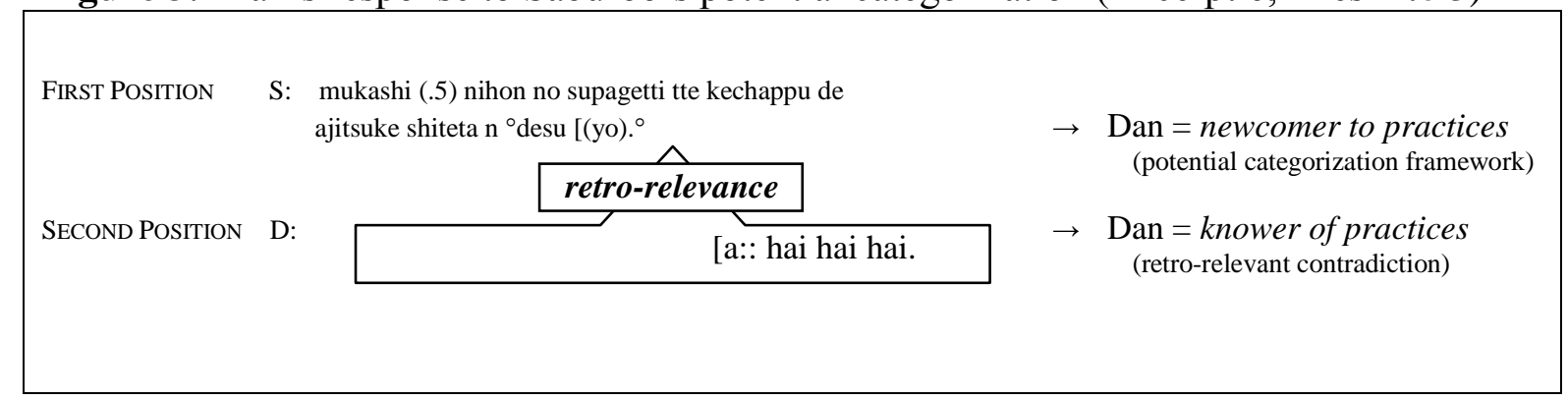

Saburoo immediately responds to Dan's claim with a repair initiator, "a shittemasu?" (oh [you] know?), to which Dan replies with a minimal affirmation (in lower volume) in line 5, which instantiates a second minimal claim of knowledge. However, in line 7, Saburoo treats Dan's line 5 as being insufficient to warrant a closing of the repair sequence (note the .6 second pause), and further focuses the activity by proffering the name of the dish indexed by his line 1, "spaghetti Neapolitan." Saburoo's action of providing the name of the dish seems to challenge Dan's line 3 epistemic claim and to refresh the potential relevance of a categorization framework wherein Saburoo is cast as a Japanese old-timer with epistemic authority, and Dan as a foreign newcomer. Just at this point, however, Dan overlaps Saburoo's utterance to begin production of his lines 8 and 9, a first priority response which notably upgrades his lines 3 and 5 from a general epistemic claim to an account of personal experiential knowledge. In particular, Dan states that his wife often used to make spaghetti Neapolitan.

\footnotetext{
${ }^{9}$ It may be noted that Bilmes (1995) argues that first priority responses should be produced as
} early as possible. 
(6b) Detail of Lines 7, 8 and 9

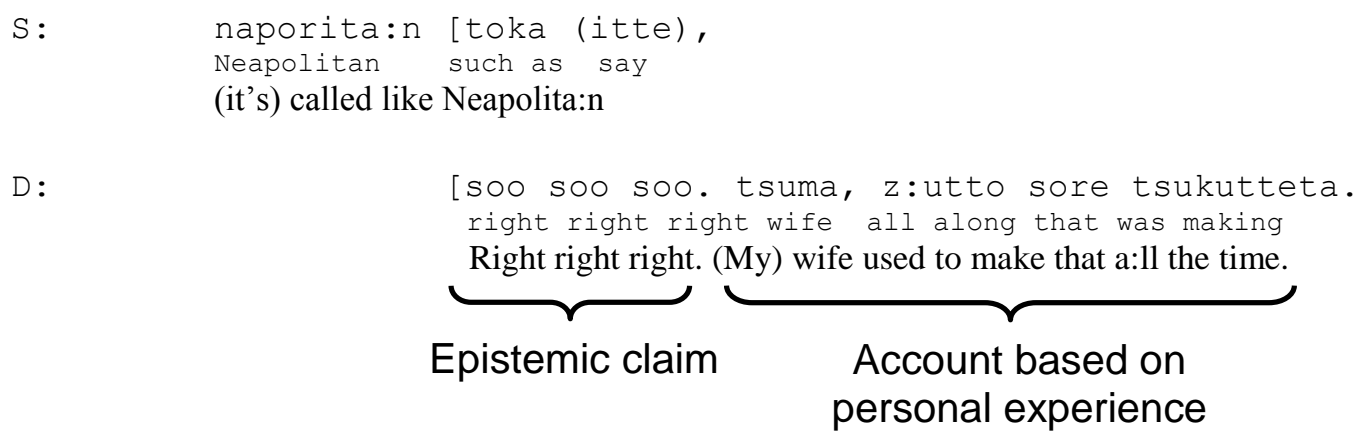

This utterance, and Saburoo's response to it, warrant a bit of background information to make them fully interpretable: Dan's wife (whom Saburoo also knows) is Japanese. Thus, this utterance indexes a membership category glossable as spouse of a Japanese. Furthermore, by assembling Dan into that category, Dan's lines 8 and 9 suggest that he has special access to Japanese practices that would not normally be available to foreigners. It may also be noted that Dan specifically formulates his utterance in a manner so as to propose that his wife used to make this particular dish frequently and over a considerable period of time, that is, "tsuma, z:utto sore tsukutteta" ([my] wife used to make that a:ll the time).

(6c) Detail of Lines 8 and 9

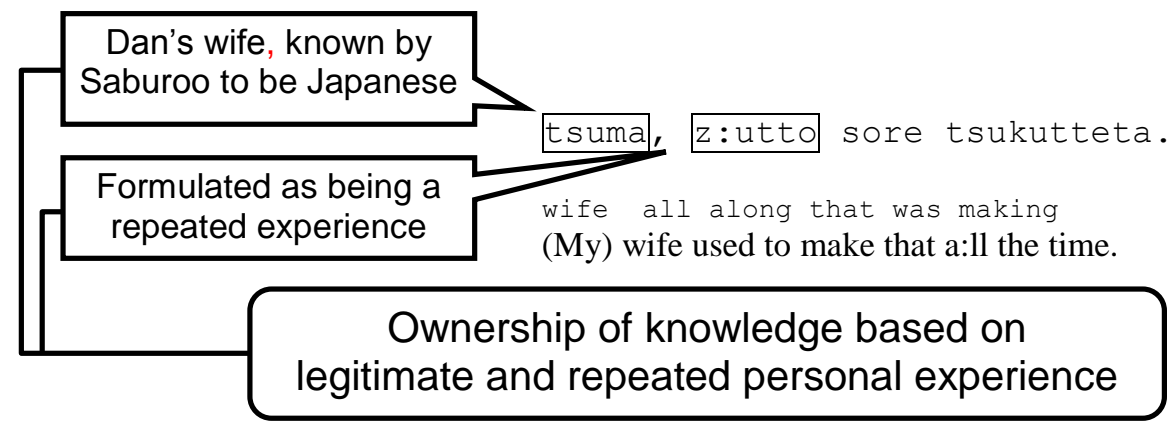

Then, in line 10, Saburoo does a confirmation check produced with a marked raise in volume and animation, which, taken together, seem to index an affective stance (Ochs 1993, 1996) of great surprise. ${ }^{10}$ These actions are hearable as claiming a change of state in regard to Dan's category-bound epistemic entitlements and related categorizability as equal knower of this particular dish. In line 11, Dan provides the confirmation token made relevant by Saburoo's line 10, which endorses Saburoo's displayed update in understanding.

Dan's sequentially deployed actions in lines 3, 5, 8, and 9 are delicately designed in retro-relevant response to Saburoo's lines 1, 2, 4, and 7. In this manner, Dan's contributions collectively build up a contradiction to the potential categorization framework proposed by Saburoo, and in so doing simultaneously display Dan's own recognition and understanding of that categorization framework - it is on this publicly displayed understanding that the present analysis is grounded. Simultaneously, they

${ }^{10}$ The transcript does not do justice to the highly animated prosodic qualities of Saburoo's line 
work to categorize Dan as a long-time knower in that they claim a longstanding, experiential knowledge about this particular culinary practice; in sequential response to Dan's categorization work, Saburoo displays an affective stance of surprise, which the participants then treat as making relevant a co-display of knowledge, thus recategorizing Dan as equal knower, rather than as unknowing foreign newcomer (see, e.g., Heritage \& Raymond 2005; Heritage 2012; Raymond \& Heritage 2006). In this way, the participants pre-empt the initially projected informing sequence, and make relevant to their interaction a co-constructed display of category-bound knowledge in the form of reminiscing. ${ }^{11}$ Furthermore, by not doing an informing sequence, the participants are able to publicly co-display their understandings of the non-categorizability of Dan as unknowing foreign newcomer, and his categorizability as equal knower. Thus, the participants' displayed functioned to make relevant (or irrelevant) certain sequences, and these sequences simultaneously and reflexively worked to make the categories visible as categories, and as specific categories.

\section{Concluding remarks}

In this essay, I have outlined a methodological framework which synthesizes conversation and membership categorization analytic notions and procedures, that is, sequential categorization analysis. In general, this framework centers around two main analytical foci. The first examines how participants associate some set of normatively and morally accountable actions, rights, obligations, entitlements, attributes, etc. (i.e., category-bound predicates; see, e.g., Jayyusi 1984; Sacks 1972a, 1972b, 1979, 1992; Watson 1978) to the various turn- and sequence-generated categories built up by their actions-in-talk, and to explicit categorial formulations (i.e. labels, metonyms, descriptions, etc.) and their indexers. The second is concerned with how the participants recognizably and relevantly accomplish the sequential organization and turn by turn management of their categorization work. The notions of rhetorical (see Edwards 1991, 1997, 1998), conditional (Schegloff 1968, 1972), and retro-relevance (see Schegloff 2007a on "retro-sequences"), along with response priority (Bilmes 1993, 1995, see also Bilmes 1988) were introduced as useful sequential analytical tools for developing a systematic, data-based analysis of these practices. While there is still much work left to be done to develop a systematic approach to the analysis of categories in talk-ininteraction, it is hoped that this essay will provide some direction for future efforts.

\section{Acknowledgements}

A previous version of this paper was presented at the $11^{\text {th }}$ Annual Conference of the International Pragmatics Association (IPrA), and benefits greatly from many of the comments received at that time. Also, I wish to express my gratitude to Arnulf

${ }^{11}$ This occurs in the sequence following line 11 (not shown), where Dan and Saburoo coconstruct a detailed description of the ingredients and methods of preparation for spaghetti Neapolitan. 
Deppermann for his insightful comments on parts of my analysis, and to Jack Bilmes, who carefully read and commented on my manuscripts. I take full responsibility, however, for any errors or misinterpretations of the data.

\section{References}

Antaki, C., and S. Widdicombe (1998) Identity as an achievement and as a tool. In C. Antaki, and S.M. Widdicombe (eds.), Identities in Talk. Thousand Oaks, CA: Sage, pp. 1-14.

Bilmes, J. (1988) The concept of preference in conversation analysis. Language in Society 17: 161-181.

Bilmes, J. (1993) Ethnomethodology, culture and implicature: Toward an empirical pragmatics. Pragmatics 3: 387-409.

Bilmes, J. (1995) Negotiation and compromise. In A. Firth (ed.), The Discourse of Negotiation: Studies of Language in the Workplace. Oxford: Pergamon Press Oxford, pp. 61-81.

Bushnell, C. (2011) Interactionally constructing practice, community, shared resources, and identity: An ethnomethodological analysis of interactions at conversation analytic data sessions in Japan. Unpublished doctoral dissertation. Honolulu, Hawai'i: University of Hawai'i at Mānoa.

Bushnell, C. (2014) Warai no tsuikyu: Ryugakusei mukeno rakugokai niokeru warai o fukumu sogokoi nitsuite. [In the pursuit of laughter: Laughter-in-interaction at a rakugo performance for foreign students]. Tsukuba Daigaku Ryugakusei Senta Nihongo Kyoiku Ronshu 29: 19-41.

Carlin, A.P. (2010) Reading “A tutorial on membership categorization” by Emanuel Schegloff. Journal of Pragmatics 42.1: 257-261.

Carroll, D. (2004) Restarts in novice turn beginnings: Disfluencies or interactional achievements? In R. Gardner, and J. Wagner (eds.), Second Language Conversations. London: Continuum, pp. 201-220.

Day, D. (1998) Being ascribed, and resisting, membership of an ethnic group. In C. Antaki, and S.M. Widdicombe (eds.), Identities in Talk. Thousand Oaks, CA: Sage, pp. 151-170.

Edwards, D. (1998) The relevant thing about her: Social identity categories in use. In C. Antaki, and S. Widdicombe (eds.), Identities in talk. Thousand Oaks, CA: Sage, pp. 15-33.

Edwards, D. (1997) Discourse and Cognition. Thousand Oaks, CA: Sage.

Edwards, D. (1991) Categories are for talking: On the cognitive and discursive bases of categorization. Theory \& Psychology 1.4: 515-542.

Francis, D., and C. Hart (1997) Narrative intelligibility and membership categorization in a television commercial. In S. Hester, and P. Eglin (eds.), Culture in Action: Studies in Membership Categorization Analysis, Studies in ethnomethodology and conversation analysis. Washington, DC: International Institute for Ethnomethodology and Conversation Analysis \& University Press of America, pp. 123-151.

Gafaranga, J. (2000) Medium repair vs. other-language repair: Telling the medium of a bilingual conversation. International Journal of Bilingualism 4.3: 327-350.

Garfinkel, H. (1967) Studies in Ethnomethodology. Englewood Cliffs, N.J: Prentice-Hall. 
Goodwin, C. (1980) Restarts, pauses, and the achievement of a state of mutual gaze at turn-beginning. Sociological Inquiry 50.3-4: 272-302.

Goodwin, C. (2007) Interactive footing. In E. Holt, and R. Clift (eds.), Reporting Talk: Reported Speech in Interaction. Cambridge: Cambridge University Press, pp. 16-46.

Have, P. ten (2007) Doing Conversation Analysis (Second Edition.). Boston: Sage.

Hayashi, M. (2004) Projection and grammar: Notes on the 'action-projecting' use of the distal demonstrative are in Japanese. Journal of Pragmatics 36.8: 1337-1374.

Heritage, J. (1984) A change-of-state token and aspects of its sequential placement. In J.M. Atkinson, and J. Heritage (eds.), Structures of Social Action: Studies in Conversation Analysis. Cambridge: Cambridge University Press, pp. 299-345.

Heritage, J. (2012) The epistemic engine: Sequence organization and territories of knowledge. Research on Language \& Social Interaction 45.1: 30-52.

Heritage, J., and G. Raymond (2005) The terms of agreement: Indexing epistemic authority and subordination in talk-in-interaction. Social Psychology Quarterly 68: 15-38.

Hester, S., and P. Eglin (1997) Culture in action: Studies in membership categorisation analysis. Washington, DC: International Institute for Ethnomethodology and Conversation Analysis \& University Press of America.

Hosoda, Y. (2000) Other-repair in Japanese conversation between nonnative and native speakers. Issues in Applied Linguistics 11.1: 39-63.

Hosoda, Y. (2006) Repair and relevance of differential language expertise in second language conversations. Applied Linguistics 27.1: 25-50.

Housley, W., and R. Fitzgerald (2002) The reconsidered model of membership categorisation. Qualitative Research 2: 59-74.

Housely, W., and R. Fitzgeral (2009) Membership categorization, culture and norms in action. Discourse and Society 20: 345-362.

Hutchby, I., and R. Wooffitt (2008) Conversation Analysis (2nd ed.). Cambridge, UK: Polity.

Jayyusi, L. (1984) Categorization and the Moral Order. Boston: Routledge and K. Paul.

Jefferson, G. (1972) Side sequences. In D.N. Sudnow (ed.), Studies in Social Interaction. New York, NY: Free Press, pp. 294-333.

Jefferson, G. (1974) Error correction as an interactional resource. Language in Society 3.2: 181-199.

Jefferson, G. (1983) On exposed and embedded correction in conversation. In J.R.E. Lee, and G. Button (eds.), Talk and Social Organization. Clevedon, UK: Multilingual Matters, pp. 86-100.

Jefferson, G. (1986) Notes on "latency" in overlap onset. Human Studies 9.2/3: 153-183.

Jefferson, G. (1989) Notes on a possible metric which provides for a "standard maximum" silence of approximately one second in conversation. In D. Roger, and P. Bull (eds.), Conversation: An Interdisciplinary Perspective. Clevedon: Multilingual Matters.

Jefferson, G. (2004) Glossary of transcript symbols with an introduction. In G.H. Lerner (ed.), Conversation analysis: Studies from the first generation. Amsterdam: John Benjamins Publishing Company, pp. 13-31. 
Kamio, A. (1997) Territory of Information. Amsterdam: John Benjamins Publishing Company.

Kasper, G. (2006) Beyond repair: Conversation analysis as an approach to SLA. AILA Review 19: 83-99.

Lepper, G. (2000) Categories in Text and Talk: A Practical Introduction to Categorization Analysis. London: Sage.

Mori, J. (2004) Negotiating sequential boundaries and learning opportunities: A case from a Japanese language classroom. The Modern Language Journal 88.4: 536-550.

Nguyen, H.T. (2008) Sequence organization as local and longitudinal achievement. Text \& Talk 28.4: 501-528.

Nguyen, H. t., and G. Kasper (eds.) (2009) Talk-in-interaction: Multilingual perspectives. Honolulu, HI: National Foreign Language Resource Center.

Ochs, E. (1993) Constructing social identity: A language socialization perspective. Research on Language \& Social Interaction 26.3: 287.

Ochs, E. (1996) Linguistic resources for socializing humanity. In J. Gumperz, and S. Levinson (eds.), Rethinking linguistic relativity. Cambridge: Cambridge University Press, pp. 407-438.

Omori, M. (2008) Constitution of interculturality in an English conversational exchange program. Paper presented at the 18th International Congress of Linguistics, Korea University, Seoul, Korea.

Onuki, T., and H. Matsuki (2003) Hankoukoudou no kousei to seiin kategoriika jissen: Iwayuru 'Ashikaga jiken' ni okeru seishin kantei wo megutte. [The practice of membership categorization in constituting criminal action: A look at the psychological evaluation in the so-called "Ashikaga" case] Japanese Journal of Sociological Criminology 28: 68-81.

Paoletti, I. (1998) Handling 'incoherence' according to the speaker's on-sight categorization. In C. Antaki, and S. Widdicombe (eds.), Identities in Talk. Thousand Oaks, CA: Sage, pp. 171-190.

Park, J. (2007) Co-construction of nonnative speaker identity in cross-cultural interaction. Applied Linguistics 28.3: 339-360.

Psathas, G. (1999) Studying the organization in action: Membership categorization and interaction analysis. Human Studies 22.2: 139-162.

Raymond, G., and J. Heritage (2006) The epistemics of social relations: Owning grandchildren. Language in Society 35.5: 677-705.

Richards, K. (2006) 'Being the teacher': Identity and classroom conversation. Applied Linguistics 27.1: 51-77.

Sacks, H. (1972a) An initial investigation of the usability of conversational data for doing sociology. In D. Sudnow (ed.), Studies in Social Interaction. New York: Free Press, pp. 31-74.

Sacks, H. (1972b) On the analysability of stories by children. In J.J. Gumperz, and D.H. Hymes (eds.), Directions in Sociolinguistics; the Ethnography of Communication. New York: Holt, Rinehart and Winston, pp. 325-345.

Sacks, H. (1975) Everyone has to lie. In M. Sanchez, and B.G. Blount (eds.), Sociocultural Dimensions of Language Use. New York: Academic Press, pp. 57-79.

Sacks, H. (1979) Hotrodder: A revolutionary category. In G. Psathas (ed.), Everyday language: Studies in ethnomethodology. New York: Irvington Publishers, pp. 7-14. 
Sacks, H. (1992) Lectures on Conversation. (Vols. 1-2). Oxford: Blackwell.

Sacks, H., E.A. Schegloff, and G. Jefferson (1974) A simplest systematics for the organization of turntaking for conversation. Language 50.4: 696-735.

Schegloff, E.A. (1968) Sequencing in conversational openings. American Anthropologist 70.6: 10751095 .

Schegloff, E.A. (1972) Notes on a conversational practice: Formulating place. In D. Sudnow (ed.), Studies in social interaction. New York: The Free Press, pp. 75-119.

Schegloff, E.A. (1979) The relevance of repair to syntax-for-conversation. In T. Givón (ed.), Discourse and Syntax. New York: Academic Press, pp. 261-286.

Schegloff, E.A. (1980) Preliminaries to preliminaries: “Can I ask you a question?” Sociological Inquiry 50.3-4: 104-152.

Schegloff, E.A. (1987) Recycled turn beginnings: A precise repair mechanism in conversation's turntaking organisation. In Talk and Social Organisation. Clevedon: Multilingual Matters, pp. 70-85.

Schegloff, E.A. (1990) On the organization of sequences as a source of "coherence" in talk-in-interaction. In B. Doval (ed.), Conversational organization and its development. NJ: Ablex, pp. 51-77.

Schegloff, E.A. (1991) Conversation analysis and socially shared cognition. In L.B. Resnick, J.M. Levine, and S.D. Teasley (eds.), Perspectives on socially shared cognition. Washington, D.C.: American Psychological Association, pp. 150-171.

Schegloff, E.A. (1992) Repair after next turn: The last structurally provided defense of intersubjectivity in conversation. American Journal of Sociology 97.5: 1295-1345.

Schegloff, E.A. (1996) Turn organization: One intersection of grammar and interaction. In Interaction and grammar. Cambridge: Cambridge University Press, pp. 52-133.

Schegloff, E.A. (1997) Third turn repair. In G. Guy, C. Feagin, D. Schiffrin, and J. Baugh (eds.), Towards a Social Science of Language 2. Amsterdam/Philadelphia: John Benjamins Publishing Company, pp. 261286.

Schegloff, E.A. (2000a) Overlapping talk and the organization of turn-taking for conversation. Language in Society 29.1: 1-63.

Schegloff, E.A. (2000b) When “others" initiate repair. Applied Linguistics 21.2: 205-243.

Schegloff, E.A. (2006) Interaction: The infrastructure for social institutions, the natural ecological niche for language, and the arena in which culture is enacted. In N. Enfield, and S. Levinson (eds.), Roots of Human Sociality: Culture, Cognition and Interaction. Oxford: Berg, pp. 70-96.

Schegloff, E.A. (2007a) Sequence Organization in Interaction: Volume 1: A Primer in Conversation Analysis. Cambridge: Cambridge University Press.

Schegloff, E.A. (2007b) A tutorial on membership categorization. Journal of Pragmatics 39.3: 462-482.

Schegloff, E.A. (2007c) Categories in action: Person-reference and membership categorization. Discourse Studies 9: 433-461.

Schegloff, E.A., and H. Sacks (1973) Opening up closings. Semiotica 8.4: 289-327. 
Seedhouse, P. (2004) The Interactional Architecture of the Language Classroom: A Conversation Analysis Perspective. Malden: Blackwell.

Stokoe, E. (2009) Doing actions with identity categories: Complaints and denials in neighbor disputes. Text \& Talk 29.1: 75-97.

Stokoe, E. (2012) Moving forward with membership categorization analysis: Methods for systematic analysis. Discourse Studies 14.3: 277-303.

Talmy, S. (2008) The cultural productions of the ESL student at Tradewinds High: Contingency, multidirectionality, and identity in L2 socialization. Applied Linguistics 29.4: 619-644.

Tanaka, H. (1999a) Grammar and social interaction in Japanese and Anglo-American English: The display of context, social identity and social relation. Human Studies 22.2: 363-395.

Tanaka, H. (1999b) Turn-taking in Japanese Conversation: A Study in Grammar and Interaction. Amsterdam: John Benjamins Publishing Company.

Tanaka, H. (2000) The particle ne as a turn-management device in Japanese conversation. Journal of Pragmatics 32.8: 1135-1176.

Watson, R. (1978) Categorisation, authorisation and blame-negotiation in conversation. Sociology 12: 105-113.

Watson, R. (1994) Catégories, séquentialité et ordre social: Un nouveau regard sur l'oeuvre de Sacks. In B. Fradin, L. Quére', and J. Widmer (eds.), L'Enquête Sur Les Catégories. Paris: École des Hautes Études en Sciences Sociales, pp. 151-184.

Watson, R. (1997) Some general reflections on 'categorization' and 'sequence' in the analysis of conversation. In S. Hester, and P. Eglin (eds.), Culture in action: Studies in membership categorization analysis. Washington, DC: International Institute for Ethnomethodology and Conversation Analysis \& University Press of America, pp. 49-76.

Wong, J. (2000) Delayed next turn repair initiation in native/non-native speaker English conversation. Applied Linguistics 21.2: 244-267.

Zimmerman, D.H. (1998) Identity, context and interaction. In Identities in talk. Thousand Oaks, CA: Sage, pp. 87-106.

CADE BUSHNELL received his Ph.D. in Japanese Linguistics at the University of Hawai'i at Manoa. He is currently an associate professor of Japanese studies at the University of Tsukuba. His research interests include participation, membership and learning; laughter and language play; and identity - all particularly in the case of second language users. Recent publications include "Talking the talk: The interactional construction of community and identity at conversation analytic data sessions in Japan"(Human Studies 35: 583-605), and "'Lego my keego!': An analysis of language play in a beginning Japanese as a foreign language classroom" (Applied Linguistics 30.1: 49-69).

Address: University of Tsukuba, International Student Center, 1-1-1 Tennodai, Tsukuba, Ibaraki 3058577, Japan. E-mail: buu@intersc.tsukuba.ac.jp 